\title{
openheart Low rate of and rapid attention to inappropriate ICD shocks with remote device and rhythm monitoring: a qualitative study
}

\author{
Emma Sandgren, ${ }^{1}$ Cecilia Rorsman, ${ }^{1}$ Johan Engdahl, ${ }^{2}$ Nils Edvardsson ${ }^{3}$
}

To cite: Sandgren $E$, Rorsman C, Engdahl J, et al. Low rate of and rapid attention to inappropriate ICD shocks with remote device and rhythm monitoring: a qualitative study. Open Heart 2015;2:e000249. doi:10.1136/openhrt-2015000249

Received 7 February 2015 Revised 1 July 2015 Accepted 3 July 2015

\section{ABSTRACT}

Objectives: Inappropriate shocks are unpleasant and painful. We hypothesise that remote monitoring and careful attention to known and incident atrial fibrillation (AF) can reduce inappropriate shocks to a very low level in clinical praxis.

Methods: Altogether 259 patients with implantable cardioverter defibrillator implanted for secondary $(S, n=113)$ and primary $(P, n=146)$ prevention were followed via remote monitoring. At implant, $42 \mathrm{~S}$ (37\%) and $54 \mathrm{P}(37 \%)$ patients had known AF.

Results: Inappropriate shocks, all but five due to AF, occurred in $7 \mathrm{~S}(6.2 \%)$ and $11 \mathrm{P}(7.5 \%)$, and there were only inappropriate shocks in 5/7S and in 8/11P. They occurred in four of $42 \mathrm{~S}(9.5 \%)$ with and in three of $71 \mathrm{~S}(4.2 \%)$ without known $\mathrm{AF}$, and in seven of $54 \mathrm{P}$ $(13 \%)$ with and in four of $92 \mathrm{P}(4.3 \%)$ without known AF. The median time from shock to action was 5 and 1 day, respectively. Actions were medication with amiodarone, $\beta$ blockers, $\beta$ blockers+amiodarone or $\beta$ blockers+digoxin $(n=5), \beta$ blockers+insertion of an atrial lead $(n=1)$, replacement of a fractured lead $(n=2)$, reprogramming in combination with $\beta$ blockers, digoxin or amiodarone $(n=4)$, reprogramming $(n=2)$ and none $(n=4)$. After action, four further inappropriate shocks occurred during more than 2 years of followup, all due to AF.

Conclusions: Inappropriate shocks occurred at a low rate and most often because of AF known at implant. Remote monitoring enabled rapid action, after which few inappropriate shocks occurred over more than 2 years. Attention to known and incident AF was the most important action to reduce inappropriate shocks.

\footnotetext{
${ }^{1}$ Department of Medicine, Halland Hospital, Varberg, Sweden

${ }^{2}$ Department of Medicine, Halland Hospital, Halmstad, Sweden

${ }^{3}$ Sahlgrenska Academy, Sahlgrenska University Hospital, Göteborg, Sweden
}

Correspondence to Dr Emma Sandgren; emma.sandgren@ regionhalland.se

\section{INTRODUCTION}

Implantable cardioverter defibrillator (ICD) therapy improves survival when prescribed for secondary ${ }^{1}$ as well as for primary prevention. $^{2-4}$ However, ICD treatment may be either appropriate or inappropriate, and if given inappropriately to patients in the awake state, only a few shocks are enough to induce lasting psychological distress. ${ }^{5}{ }^{6}$ In addition, shocks can be arrhythmogenic. ${ }^{7} 8$

\section{KEY MESSAGES}

What is already known about this subject?

- Supraventricular tachyarrhythmias may cause inappropriate shocks.

- Implantable cardioverter defibrillator shocks in the awake state are unpleasant and only a few are needed to cause lasting distress and a reduced quality of life.

\section{What does this study add?}

- Inappropriate shocks are often caused by supraventricular tachyarrhythmias that are known at implant but not adequately treated.

- Remote monitoring enables early detection and treatment of arrhythmias that cause inappropriate shocks.

- Early action after detection reduces the risk of further inappropriate shocks.

How might this impact on clinical practice?

- Increased attention to atrial fibrillation (AF) known at implant can reduce subsequent inappropriate shocks.

- Early attention to new AF can reduce subsequent inappropriate shocks.

- More wide-spread routine use of remote monitoring may be justified.

The incidence of inappropriate shocks varied from $9 \%$ to $11.5 \%$ in two studies over 2 years of follow-up, ${ }^{9} 10$ and $13 \%$ in another trial with 3-year and 4-year follow-up. ${ }^{11}$ A history of AF, smoking and antecedentappropriate shock were predictors of inappropriate shocks. ${ }^{9} 1112$ Many programmable ICD parameters have an effect on the delivered device therapy, and studies on the efficacy and safety of ATP compared to shocks for fast ventricular tachycardias ${ }^{13}$ are representative of current standard programming. In primary and secondary prevention patients, a reduction of both appropriate and inappropriate shocks was achieved by programming higher detection rates or prolonged detection 
times. ${ }^{15-17}$ New detection algorithms are under development and evaluation. ${ }^{18} 19$ On the other hand, dualchamber arrhythmia discrimination algorithms have not been proven to reduce the number of patients who experience inappropriate therapy, even if the number of inappropriately treated episodes is reduced. ${ }^{20}{ }^{21}$ Recommendations for optimal ICD programming are continually being published, ${ }^{16} 22{ }^{23}$ some of which were recently summarised and reviewed. ${ }^{24}$

Remote monitoring of device function and cardiac rhythm provides opportunities to early on detect malfunction or significant arrhythmias, ${ }^{25-27}$ and enables prompt action when necessary. Remote monitoring may also be time-saving and cost-effective. ${ }^{28}{ }^{29}$ We hypothesised that remote ICD monitoring in combination with careful attention to known and incident $\mathrm{AF}$ would keep the incidence of inappropriate shocks at a low level, and we present our experience of remote monitoring of ICD treatment at a medium-sized Swedish hospital, according to SQUIRE publication guidelines. ${ }^{30}$

\section{PATIENTS AND METHODS}

This is a single-site retrospective observational study at a Swedish hospital with a catchment area of 300000 inhabitants. Three physicians implanted the ICDs during the recruitment period. At outpatient visits two physicians and/or two trained device nurses routinely checked device properties, counters and histograms. The nurses independently performed tests and programming of stimulation thresholds and had access to a back-up physician, who also adjudicated rhythm strips and provided prescriptions for medication, when appropriate. The study was performed as part of the quality assurance programme. The purpose was to study the time to detection and action following arrhythmias resulting in shock, and how these actions affected the risk of further inappropriate or appropriate shocks.

All consecutive patients who received an ICD with remote monitoring $(\mathrm{n}=259)$ between 2004 and 2013 were included in this analysis, and there were no exclusion criteria. The devices were manufactured by Medtronic (Minneapolis, Minnesota, USA, $\mathrm{n}=177$ ), Biotronik (Berlin, Germany, $\mathrm{n}=70$ ) or St Jude Medical (Saint Paul, Minnesota, USA, $\mathrm{n}=12$ ) at Halland's hospital, Varberg. Devices included single-chamber ICDs $(n=77)$, dual-chamber ICDs $(n=78)$ and cardiac resynchronisation therapy devices with defibrillation capabilities (CRT-D) $(\mathrm{n}=104)$. A CRT-D was usually prescribed to heart failure patients without any prior malignant arrhythmias $(n=76)$, but the device was also chosen for secondary prevention patients with signs of heart failure or a low EF $(n=28)$.

Device programming was performed on an individual basis. However, the most common ICD programming used for secondary prevention patients was a ventricular tachycardia (VT) zone $\geq 20 \mathrm{bpm}$ slower than the slowest VT and NID (number of intervals for detection) 100, a fast VT zone 188-221 bpm via VF counter and a VF zone $\geq 222 \mathrm{bpm}$ (NID 30/40). The corresponding limits for primary prevention patients were a VT zone $\geq 167 \mathrm{bpm}$ (NID 100), a fast VT zone $\geq 188-221$ bpm via VF counter and a VF zone $\geq 222 \mathrm{bpm}$ (NID 30/40).

In the retrospective analysis, patients and their device-related data were retrieved through the remote monitoring system from the respective manufacturer, either CareLink, Home Monitoring or Merlin. In patients with Medtronic devices, shock therapy was identified via Discovery Link and, in case of device replacement, also via transmissions in CareLink. In patients with Biotronik or St Jude Medical devices, transmissions in each remote monitoring system were adjudicated. The follow-up period was from when the patient was connected to a remote monitoring system until the death of the patient $(n=23)$, a move to another location $(n=2)$, device explantation due to heart transplant $(n=3)$, deactivation of device $(n=1)$, or until the end of March 2014.

An inappropriate shock was defined as an episode starting with a shock not delivered for VT or VF, and ending if and when sinus rhythm was redetected by the device. Accordingly, it was possible for more than one shock to occur within the same episode. All device-registered episodes were counted, regardless of the time between episodes. Inappropriate shocks were categorised as to the cause, for example, $\mathrm{AF}$, other supraventricular tachycardia, sinus tachycardia or abnormal sensing.

In all patients, the indication for ICD therapy, the LVEF, concomitant conditions and risk scores, presence of known AF, any rhythm and/or rate control medication and anticoagulation/antithrombotic treatment were recorded, as well as the programmed ICD settings including therapies for each zone, activated discriminators and if $\mathrm{AF}$ alert was activated. In addition, $\mathrm{P}$ and $\mathrm{R}$ sensed amplitudes were identified as well as the proportion of ventricular stimulation.

\section{STATISTICAL METHODS}

Continuous variables are reported as mean and SD. Selected proportions are reported with a 95\% CI. For continuous variables, student's t test was used. For categorical data, Fishers exact test, $\chi^{2}$ test and MannWhitney test were used. Two-tailed tests were applied. A probability value of $<0.05$ was regarded as significant. Data were processed and analysed using Microsoft Excel 2010 software.

\section{RESULTS}

From a total of 379 patients with an ICD, 259 patients, 202 of them men (78\%), were equipped with remote monitoring. Their mean age at implant was 64.7 \pm 12 years. ICDs were implanted for secondary prevention in 113 and for primary prevention in 146 patients. The baseline demographics are shown in table 1 . The 
Table 1 Baseline demographics and comorbidities in primary and secondary prevention patients

\begin{tabular}{|c|c|c|c|}
\hline Parameters & $\begin{array}{l}\text { Secondary } \\
(n=113)\end{array}$ & $\begin{array}{l}\text { Primary } \\
(n=146)\end{array}$ & p Value \\
\hline Age, years & $64.7 \pm 12$ & $65 \pm 12$ & NS \\
\hline Male & $94(83)$ & $108(74)$ & NS \\
\hline Follow-up, months & $39 \pm 24$ & $30 \pm 22$ & $<0.001$ \\
\hline $\begin{array}{l}\text { Ischaemic heart } \\
\text { disease }\end{array}$ & $69(61)$ & $73(50)$ & NS \\
\hline $\begin{array}{l}\text { Left ventricular } \\
\text { ejection fraction }\end{array}$ & $40 \pm 14$ & $29 \pm 10$ & $<0.001$ \\
\hline $\begin{array}{l}\text { History of atrial } \\
\text { fibrillation }\end{array}$ & $42(37)$ & $54(37)$ & NS \\
\hline $\mathrm{CHADS}_{2}$ score & $1.6 \pm 1.3$ & $1.8 \pm 1.1$ & NS \\
\hline $\begin{array}{l}\mathrm{CHA}_{2} \mathrm{DS}_{2} \text {-VASc } \\
\text { score }\end{array}$ & $3.0 \pm 1.7$ & $3.1 \pm 1.6$ & NS \\
\hline $\begin{array}{l}\text { Single-chamber } \\
\text { ICD }\end{array}$ & $37(33)$ & $40(27)$ & $<0.001$ \\
\hline Dual-chamber ICD & $48(42)$ & $30(21)$ & NS \\
\hline CRT-D & $28(25)$ & $76(52)$ & NS \\
\hline
\end{tabular}

Values shown are mean \pm SD or $n(\%)$.

CRT-D, cardiac resynchronisation therapy+defibrillator; ICD, implantable cardioverter defibrillator; NS, not significant.

$\mathrm{CHADS}_{2}$ and $\mathrm{CHA}_{2} \mathrm{DS}_{2}$-VASc scores were $1.7 \pm 1.2$ and 3.1 \pm 1.7 , respectively.

Appropriate shocks occurred in $24(21.2 \%)$ secondary and in $15(10.3 \%)$ primary prevention patients after a mean of $19.3 \pm 19.1$ months. Sustained supraventricular tachyarrhythmias, specifically AF, were known at the time of ICD implant in $42(37 \%)$ and $54(37 \%)$ patients, respectively. The annual rates of appropriate shocks were $6.8 \%$ primary prevention patients and $18 \%$ secondary prevention patients.

Table 2 Basic demographics in patients with and without inappropriate shock (Inapp shock)

\begin{tabular}{|c|c|c|c|}
\hline $\begin{array}{l}\text { Patient } \\
\text { characteristics }\end{array}$ & $\begin{array}{l}\text { Inapp } \\
\text { shock } \\
+(n=18)\end{array}$ & $\begin{array}{l}\text { Inapp } \\
\text { shock- } \\
(n=241)\end{array}$ & p Value \\
\hline Age & $61.6 \pm 14$ & $64.8 \pm 12$ & NS \\
\hline Male & $16(89)$ & $186(77)$ & NS \\
\hline Primary prevention & $11(61)$ & $135(56)$ & NS \\
\hline Single-chamber & $5(28)$ & $72(30)$ & NS \\
\hline Dual-chamber & 7 (39) & 71 (29) & NS \\
\hline CRT-D & $6(33)$ & $98(41)$ & NS \\
\hline $\begin{array}{l}\text { Ischaemic heart } \\
\text { disease }\end{array}$ & $10(56)$ & $132(55)$ & NS \\
\hline $\begin{array}{l}\text { Left ventricular } \\
\text { ejection fraction }\end{array}$ & $33.3 \pm 13.4$ & $33.9 \pm 13$ & NS \\
\hline History of AF & $12(67)$ & $84(35)$ & 0.007 \\
\hline CHADS2 score & $1.8 \pm 1.0$ & $1.7 \pm 1.2$ & NS \\
\hline $\begin{array}{l}\text { CHA2DS2VASc } \\
\text { score }\end{array}$ & $2.8 \pm 1.5$ & $3.1 \pm 1.7$ & NS \\
\hline $\begin{array}{l}\text { Values shown are mea } \\
\mathrm{AF} \text {, atrial fibrillation; } \mathrm{CF} \\
\text { +defibrillator. }\end{array}$ & $\begin{array}{l} \pm \text { SD or } n(\%) \text {. } \\
-D, \text { cardiac re }\end{array}$ & chronisati & erapy \\
\hline
\end{tabular}

\section{Inappropriate shocks during follow-up}

Inappropriate shocks occurred in $7(6.2 \%)$ secondary and $11(7.5 \%)$ primary prevention patients after 14 \pm 19.9 months (range $0.33-55$ months) and 9.7 \pm 14.1 months (range 0.07-46 months), respectively, all but five due to AF. The annual incidence of inappropriate shocks was $2.7 \%$ and $3.8 \%$ in secondary and primary prevention patients, respectively. Baseline demographics for patients with and without inappropriate shock appear in table 2.

Five of the seven secondary and 8 of the 11 primary prevention patients only had inappropriate shocks. Inappropriate shocks occurred in 5 of 42 (11.9\%) secondary prevention patients with, and in 2 of 71 (2.8\%) patients without, known AF. In primary prevention patients, inappropriate shocks occurred in 7 of 54 (13\%) with, and 4 of $92(4.3 \%)$ without, known $\mathrm{AF}$ at the time of ICD implant. The annual rate of incident AF was $5.3 \%$ in secondary and $5 \%$ in primary prevention patients. In the primary prevention patients, 10 of 11 had one, and one patient, two, inappropriate shocks before diagnosis and action. In secondary prevention patients, six had one, and one had two, inappropriate shocks before diagnosis and action. There were two further inappropriate shocks in each group during the remainder of the follow-up, for the two primary prevention patients at 5 and 11 months, respectively, after the first inappropriate shock, and for the two secondary prevention patients at 4.6 and 29 months, respectively. Five inappropriate shocks (two in primary and three in secondary prevention patients) were not caused by AF. Three of these were caused by sinus tachycardia, one by $\mathrm{T}$ wave oversensing and one by noise.

\section{Prevalent versus incident AF}

$\mathrm{AF}$ was known at implant in $37 \%$ of the patients in each group, and in total, $9.4 \%$ and $85.4 \%$ of these patients had pharmacological agents used for rhythm $(n=9)$ or rate $(n=82)$ control. In the secondary prevention group, $14 \%$ had rhythm control and $76 \%$ rate control agents, as compared with $6 \%$ and $93 \%$ in the primary prevention group, respectively. The proportions of patients with known $\mathrm{AF}$ who had inappropriate shocks were $11.9 \%$ in secondary and $13 \%$ in primary prevention patients. Rhythm or rate control therapy was equally prevalent in patients with and without inappropriate shocks.

A first-ever diagnosis of $\mathrm{AF}$ was obtained in $16.9 \%$ $(12 / 71)$ of secondary and $13 \%$ (12/92) of primary prevention patients, representing an annual rate of $5.3 \%$ vs $5.0 \%$, respectively. Among patients with known AF, $86.5 \%$ were already on anticoagulation at implant. A first ever diagnosis of AF led to initiation of anticoagulation in $75 \%$ of the patients.

\section{Time to inappropriate shock and from shock to action}

The time to the first inappropriate shock after ICD implantation appears in figure 1. In secondary 
Figure 1 Kaplan-Meier curves showing the time in months to the first inappropriate shock from the start of remote monitoring in primary and secondary prevention patients. There was no statistically significant difference between the two groups. Group 1 $(n=146)$ contains the primary and group $2(n=113)$ the secondary prevention patients.

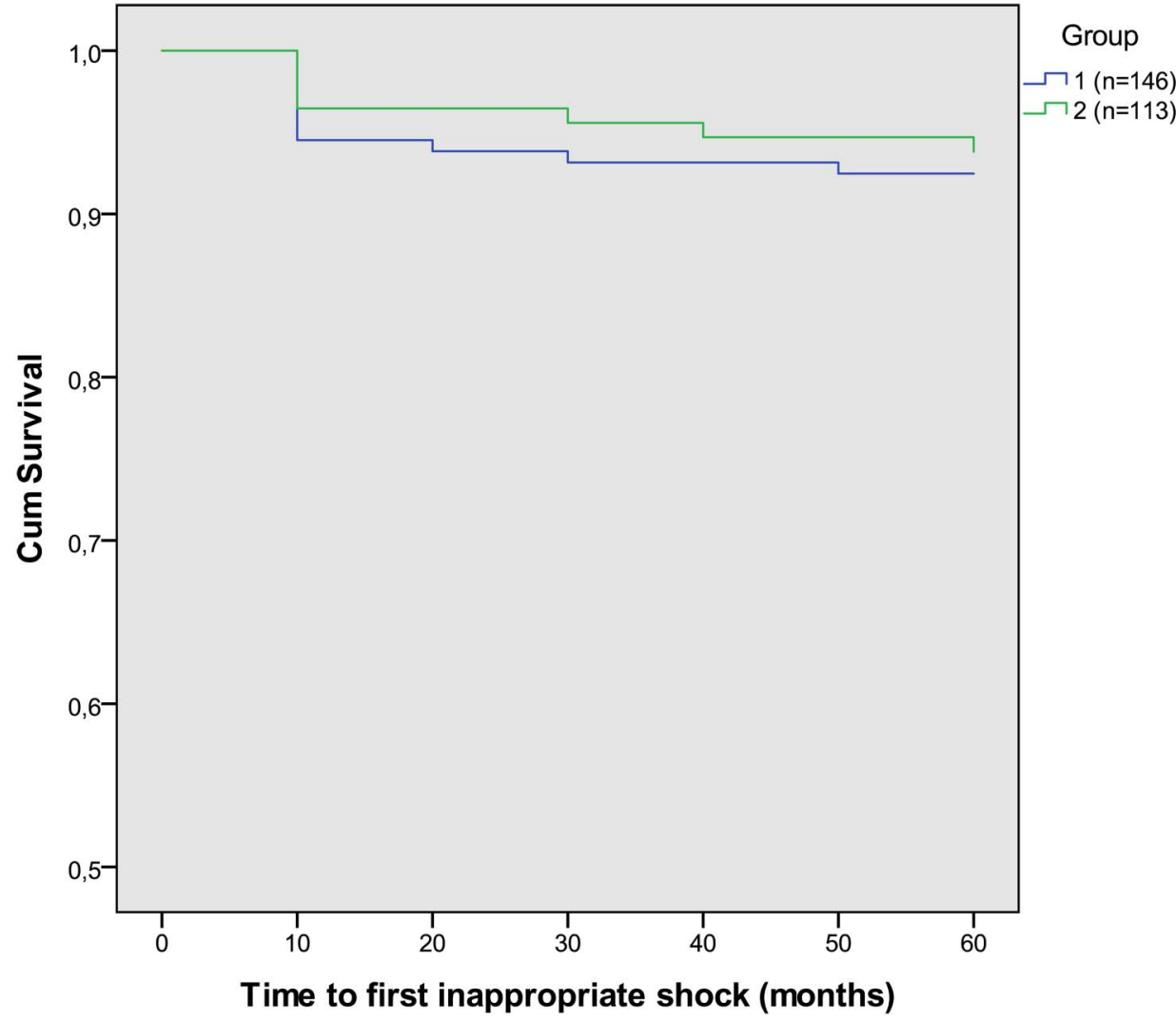

prevention patients with inappropriate shocks, the median time to the first inappropriate shock from the start of remote monitoring was 5 months, range $0.33-55$ months. The median time from shock to action was
5 days, range $0-25$ days (figure 2 ). In one patient, action occurred only after a second inappropriate shock, occurring 3 days after the first one. The remaining follow-up time was $43 \pm 29.7$ months (range 5-88 months) and two
Figure 2 Time in days from inappropriate shock to action in primary and secondary prevention patients. There was no statistically significant difference between the two groups.

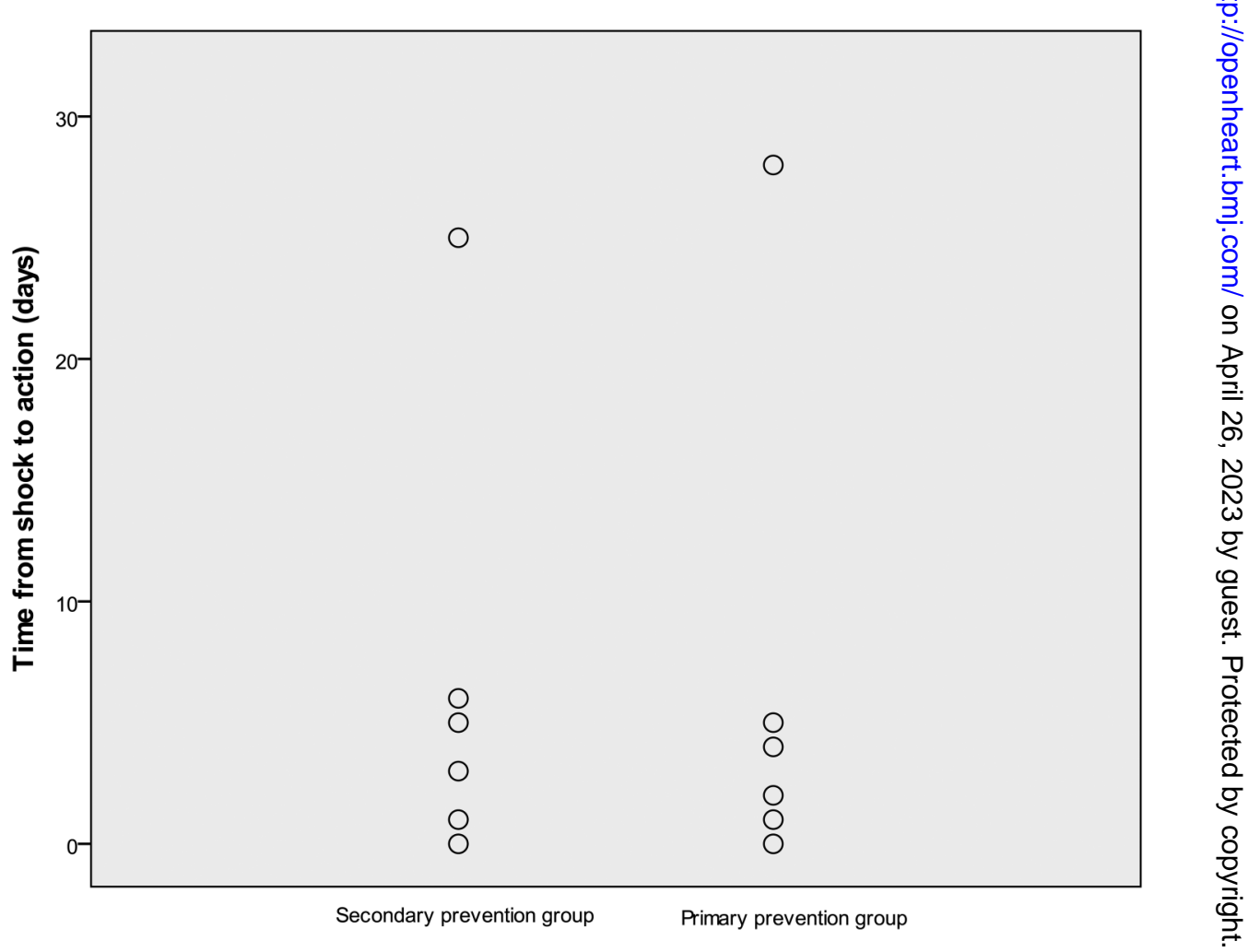


patients had one further inappropriate shock after 4.6 and 29 months, respectively, both due to recurrent AF.

In primary prevention patients with inappropriate shocks, the median time to the first inappropriate shock was 3 months, range $0.067-47$ months (figure 1), and the median time from the first shock to action was 1 day, range 0-28 days (figure 2). In one patient, action occurred only after a second inappropriate shock, occurring 5 days after the first one. The remaining follow-up was 37.5 \pm 20.8 months (range 7-67) and two patients had one further inappropriate shock after 5 and 11 months, respectively, both due to recurrent AF.

\section{Actions following inappropriate shocks}

In the primary prevention group, eight patients with one inappropriate shock each, received an atrial lead due to intermittent $\mathrm{AF}+\beta$ blockers $(\mathrm{n}=1), \beta$ blockers $+\mathrm{VF}$ zone changed 222-250 bpm $(n=1)$, amiodarone $(n=2)$, new lead due to lead fracture $(n=1)$ and no action $(n=3)$. Three patients with two inappropriate shocks each, received $\beta$ blockers $(n=1), \beta$ blockers+amiodarone $(\mathrm{n}=1)$ and no action $(\mathrm{n}=1)$.

In the secondary prevention group, four patients with one inappropriate shock each, received $\beta$ blockers+VT zone changed 150-167 bpm $(n=1)$, amiodarone $+V T$ zone changed 188-194 bpm+VF zone changed 230$250 \mathrm{bpm}(\mathrm{n}=1)$, VT2 zone changed 158-182 bpm+VF zone changed 200-222 bpm $(\mathrm{n}=1)$ and $\mathrm{VF}$ zone changed 207-222 bpm. Three patients with two inappropriate shocks each, received a new lead due to lead fracture $(n=1), \beta$ blockers+digoxin $(n=1)$ and $\beta$ blockers +digoxin+VT2 zone changed 158-194 bpm+VF zone changed 194-222 bpm.

\section{Gender aspects in inappropriate shocks}

The number of inappropriate shocks was not significantly different between men and women, $7.9 \%$ and $3.5 \%, \mathrm{p}=0.37$, respectively. Small differences in the $\mathrm{CHADS}_{2}$ scores were noted, $1.7 \pm 1.2$ and $1.4 \pm 1.1, \mathrm{p}=0.24$, respectively, while the $\mathrm{CHA}_{2} \mathrm{DS}_{2}$-VASc scores were 3.0 \pm 1.6 and $3.3 \pm 1.7, \mathrm{p}=0.19$, respectively. Women with inappropriate shocks were younger than those without, $54.5 \pm 12.0$ vs $62.2 \pm 14.1$ years, $\mathrm{p}=0.53$, and younger than men with or without inappropriate shocks, 62.4 \pm 13.9 years and $65.6 \pm 11.1$ years, $p=0.61$, respectively.

\section{DISCUSSION \\ Main results}

Inappropriate shocks occurred at low and similar rates in patients with ICD treatment for secondary and primary prevention. AF was the dominant cause and was most often known at the time of ICD implant. A firstever diagnosis of $\mathrm{AF}$ was established at a low annual rate, and remote monitoring enabled early detection of the cause of shocks, and after appropriate early actions recurrences were rare. Six of 18 patients received more than one shock, but none more than two shocks.

\section{Reduction of inappropriate shocks by AF detection algorithms}

Algorithms that identify non-malignant arrhythmias can prevent the ICD from delivering an inappropriate shock. ${ }^{23}{ }^{24}$ Studies have confirmed a reduction of the rate of inappropriate shocks, but the clinical problem is far from solved, since only a few shocks in the awake state are enough to produce long-lasting psychological distress and fear owing to negative expectations of another shock. ${ }^{6} 79$ The most recent studies tested less aggressive programming, raising the threshold for shocks due to supraventricular tachyarrhythmia. ${ }^{25} 26$ However, while saving the patient from some inappropriate shocks, this approach does not address the negative impact of the supraventricular arrhythmias.

\section{Prevalent versus incident AF during follow-up}

While AF was the most common cause of inappropriate shocks, only a minority of the patients with known or incident AF had shock delivery. Our results imply that patients without or with insufficient rhythm or rate control were those at the highest risk of recurrent arrhythmias and inappropriate shocks. Therefore, awareness of the arrhythmia history at implant and relevant therapy is an important clinical measure for reducing inappropriate shocks.

In patients without known $\mathrm{AF}$, the first-ever $\mathrm{AF}$ is more difficult to predict. In our patients with first-ever AF, the risk scores at ICD implant were not statistically higher than in those without subsequent $\mathrm{AF}$, with a mean $\mathrm{CHADS}_{2}$ score of $1.8 \pm 1.5$ vs $1.5 \pm 1.1, \mathrm{p}=0.53$, and a mean $\mathrm{CHA}_{2} \mathrm{DS}_{2}$-VASc $3.16 \pm 1.9$ vs $2.8 \pm 1.6, \mathrm{p}=0.33$.

\section{Remote monitoring and actions following inappropriate shocks during follow-up}

The time to the first inappropriate shock was similar in patients with primary and secondary prevention with median times of 3 and 5 months. The causes of inappropriate shocks were immediately apparent in the remotely transmitted rhythm strips and led, with few exceptions, to action within 1-week. Adjustment of pharmacological treatment was the most common action, occasionally in combination with device reprogramming. True malfunction was detected once in each patient group, both times as a lead fracture leading to prompt and uncomplicated lead replacements. The fractured leads were of different kinds.

\section{Predictors of inappropriate shocks}

In the present analysis, the number of inappropriate shocks was too low to allow for a meaningful predictor analysis. However, no such analysis is needed to conclude that $\mathrm{AF}$, whether prevalent or incident, was the main cause. Thus risk factors of AF are also potential risk factors of inappropriate shocks. Device-related problems are even harder to predict, and have also decreased with improved hardware and software. 


\section{Limitations}

This is a single-centre report from a middle-sized Swedish hospital comprising the complete experience with ICD devices with remote monitoring. We cannot exclude the fact that the selection of patients may have differed from other sites, considering that the ICD implant rate is in the middle of the rates in Europe and far below that in the USA. In addition, the single centre nature of this report also means that ICD programming and response to inappropriate shocks may be biased and not always reproducible. However, this report supports the contention that ICDs can be implanted and adequately followed, and that remote detection of arrhythmias and other problems promptly leads to swift actions that solve the problems. Owing to its observational design, this report does not include a control group, which may be perceived as a limitation, but on the other hand, it allowed us to report our complete experience with remote monitoring.

\section{CONCLUSION}

Inappropriate shocks occurred at low and similar rates in patients implanted with an ICD for secondary or primary prevention, almost always due to $\mathrm{AF}$ that was known at implant. Remote monitoring enabled rapid attention and provision of medication, reprogramming or lead replacement, after which no further inappropriate shocks occurred during a follow-up of almost 3 years. Inappropriate ICD shocks remain an important clinical problem and may have various reasons, but prompt attention to known and incident AF appeared to be the single most important action to reduce the risk of inappropriate shocks.

Contributors ES, CR and NE designed the study. ES collected the data and provided the first draft of the manuscript. ES, CR, JE and NE participated in the analysis of data and provided critical reviews of the manuscript. All the authors have read and approved the final version of the manuscript.

Competing interests CR consultant fees from Medtronic. JE consultant fees from Boehringer Ingelheim, Pfizer, Bayer, AstraZeneca, Sanofi and Medtronic. NE Member of Medtronic speaking bureau.

Provenance and peer review Not commissioned; externally peer reviewed.

Open Access This is an Open Access article distributed in accordance with the Creative Commons Attribution Non Commercial (CC BY-NC 4.0) license, which permits others to distribute, remix, adapt, build upon this work noncommercially, and license their derivative works on different terms, provided the original work is properly cited and the use is non-commercial. See: http:// creativecommons.org/licenses/by-nc/4.0/

\section{REFERENCES}

1. The Antiarrhythmics versus Implantable Defibrillators (AVID) Investigators. A comparison of antiarrhythmic-drug therapy with implantable defibrillators in patients resuscitated from near-fatal ventricular arrhythmias. N Engl J Med 1997;337:1576-83.

2. Buxton $A E$, Lee KL, Fisher JD, et al. A randomized study of the prevention of sudden death in patients with coronary artery disease. Multicenter Unsustained Tachycardia Trial Investigators. N Engl J Med 1999;341:1882-90.

3. Moss AJ, Zareba W, Hall WJ, et al. Prophylactic implantation of a defibrillator in patients with myocardial infarction and reduced ejection fraction. N Engl J Med 2002;346:877-83.
4. Bardy GH, Lee KL, Mark DB, et al. Sudden Cardiac Death in Heart Failure Trial (SCD-HeFT) Investigators. Amiodarone or an implantable cardioverter-defibrillator for congestive heart failure. N Engl J Med 2005;352:225-37.

5. Noyes K, Corona E, Veazie P, et al. Examination of the effect of implantable cardioverter-defibrillators on health-related quality of life: based on results from the Multicenter Automatic Defibrillator Trial-II. Am J Cardiovasc Drugs 2009;9:393-400.

6. Prudente LA. Phantom shock in a patient with an implantable cardioverter defibrillator: case report. Am J Crit Care 2003;12:144-6.

7. Vollmann D, Luthje L, Vonhof S, et al. Inappropriate therapy and fatal proarrhythmia by an implantable cardioverter-defibrillator. Heart Rhythm 2005;2:307-9.

8. Germano JJ, Reynolds M, Essebag V, et al. Frequency and causes of implantable cardioverter-defibrillator therapies: is device therapy proarrhythmic? Am J Cardiol 2006;97:1255-61.

9. Daubert JP, Zareba W, Cannom DS, et al. Inappropriate implantable cardioverter-defibrillator shocks in MADIT II: frequency, mechanisms, predictors, and survival impact. J Am Coll Cardiol 2008;51:1357-65.

10. Klein RC, Raitt MH, Wilkoff BL, et al. Analysis of implantable cardioverter defibrillator therapy in the Antiarrhythmics Versus Implantable Defibrillators (AVID) Trial. J Cardiovasc Electrophysiol 2003;14:940-8.

11. van Rees JB, Borleffs CJ, de Bie MK, et al. Inappropriate implantable cardioverter-defibrillator shocks: incidence, predictors, and impact on mortality. J Am Coll Cardiol 2011;57:556-62.

12. Theuns DAMJ, Klootwijk APJ, Simoons ML, et al. Clinical variables predicting inappropriate use of implantable cardioverter-defibrillator in patients with coronary heart disease or nonischemic dilated cardiomyopathy. Am J Cardiol 2005;95:271-4.

13. Wathen MS, DeGroot PJ, Sweeney MO, et al. Prospective randomized multicenter trial of empirical antitachycardia pacing versus shocks for spontaneous rapid ventricular tachycardia in patients with implantable cardioverter-defibrillators: Pacing Fast Ventricular Tachycardia Reduces Shock Therapies (PainFREE Rx II) trial results. Circulation 2004;110:2591-6.

14. Grimm W, Plachta E, Maisch B. Antitachycardia pacing for spontaneous rapid ventricular tachycardia in patients with prophylactic cardioverter-defibrillator therapy. Pacing Clin Electrophysiol 2006;29:759-64.

15. Wilkoff BL, Williamson BD, Stern RS, et al. Strategic programming of detection and therapy parameters in implantable cardioverter-defibrillators reduces shocks in primary prevention patients: results from the PREPARE (Primary Prevention Parameters Evaluation) study. J Am Coll Cardiol 2008;52:541-50.

16. Moss AJ, Schuger C, Beck CA, et al. Reduction in inappropriate therapy and mortality through ICD programming. $N$ Engl J Med 2012;367:2275-83.

17. Gasparini M, Proclemer A, Klersy C, et al. Effect of long-detection interval vs standard-detection interval for implantable cardioverter-defibrillators on antitachycardia pacing and shock delivery: the ADVANCE III randomized clinical trial. JAMA 2013:309:1903-11.

18. Auricchio A, Meijer A, Kurita T, et al. Safety, efficacy, and performance of new discrimination algorithms to reduce inappropriate and unnecessary shocks: the PainFree SST clinical study design. Europace 2011;13:1484-93.

19. Lewandowski M, Przybylski A, Kuzmicz W, et al. Reduction of the inappropriate ICD therapies by implementing a new fuzzy logic-based diagnostic algorithm. Ann Noninvasive Electrocardiol 2013:18:457-66.

20. Theuns DA, Klootwijk AP, Goedhart DM, et al. Prevention of inappropriate therapy in implantable cardioverter-defibrillators: results of a prospective, randomized study of tachyarrhythmia detection algorithms. J Am Coll Cardiol 2004;44:2362-7.

21. Theuns DA, Rivero-Ayerza M, Boersma E, et al. Prevention of inappropriate therapy in implantable defibrillators: a meta-analysis of clinical trials comparing single-chamber and dual-chamber arrhythmia discrimination algorithms. Int J Cardiol 2008;125:352-7.

22. Madhavan M, Friedman PA. Optimal programming of implantable cardiac-defibrillators. Circulation 2013;128:659-72.

23. Koneru JN, Swerdlow CD, Wood MA, et al. Minimizing inappropriate or "unnecessary" implantable cardioverter-defibrillator shocks: appropriate programming. Circ Arrhythm Electrophysiol 2011;4:778-90

24. Mansour F, Khairy P. Programming ICDs in the Modern Era beyond Out-of-the Box Settings. Pacing Clin Electrophysiol 2011;34:506-20.

25. Guedon-Moreau L, Lacroix D, Sadoul N, et al. A randomized study of remote follow-up of implantable cardioverter defibrillators: safety and efficacy report of the ECOST trial. Eur Heart $J$ 2013;34:605-14. 
26. Hauck M, Bauer A, Voss F, et al. "Home monitoring" for early detection of implantable cardioverter-defibrillator failure: a single-center prospective observational study. Clin Res Cardiol 2009;98:19-24.

27. Wang H, Hua W, Ding LG, et al. Home monitoring system improves the detection of ventricular arrhythmia and inappropriate shock. Chin Med J 2012;125:3421-4.

28. Raatikainen MJ, Uusimaa P, van Ginneken MM, et al. Remote monitoring of implantable cardioverter defibrillator patients: a safe, time-saving, and cost-effective means for follow-up. Europace 2008;10:1145-51.

29. Costa PD, Reis AH, Rodrigues PP. Clinical and economic impact of remote monitoring on the follow-up of patients with implantable electronic cardiovascular devices: an observational study. Telemed $\mathrm{J}$ E Health 2013;19:71-80.

30. Davidoff F, Batalden P, Stevens D, et al. Publication guidelines for quality imporovement in health care: evolution of the SQUIRE project. BMJ 2009;338:a3152. 